\title{
The Effect of Community-Based Reproductive Health Communication Interventions on Contraceptive Use Among Young Married Couples in Bihar, India
}

\begin{abstract}
CONTEXT: Contraceptive use among young couples in India is low, and early childbearing and short birth intervals are common. The PRACHAR Project, an ongoing intervention in Bihar, seeks to increase contraceptive use for delaying and spacing births through communication interventions.
\end{abstract}

\begin{abstract}
METHODS: Random samples of married women younger than 25 with no more than one child were surveyed in
\end{abstract} 2002-2003, before PRACHAR was implemented $(N=1,995)$, and in 2004,21-27 months after implementation $(N=2,080)$. Contraceptive demand and use, and related attitudes and knowledge, were assessed in the two surveys in both intervention areas and comparison areas. Logistic regression was used to assess the effect of the interventions on these indicators.

RESULTS: Contraceptive use was very low (2-6\%) at baseline in both comparison and intervention areas. Demand for contraception increased from $25 \%$ at baseline to $40 \%$ at follow-up in intervention areas, but remained virtually unchanged in comparison areas. At follow-up, contraceptive use had risen in both areas, but the adjusted odds of use in intervention areas were 3.8 times those in comparison areas. Women in intervention areas had elevated odds of knowing that fertility varies during the menstrual cycle, and of agreeing that early childbirth can be harmful and that contraceptive use is necessary and safe for delaying first births (odds ratios, 1.6-3.0).

CONCLUSION: Culturally appropriate, community-based communication programs that target youth and those who influence their decisions can create demand for contraception among young couples and lead to increased contraceptive use.
By Elkan E.Daniel, Rekha Masilamani and Mizanur Rahman

Elkan E. Daniel is advisor, and Rekha Masilamani is country representative, at Pathfinder International/India

New Delhi, India.

Mizanur Rahman is senior research advisor, Pathfinder International, Watertown, MA, USA
India is home to one-sixth of the world's population, and to $30 \%$ of youth aged $10-24 .{ }^{1}$ There are more than 211 million 15-24-year-olds in India, ${ }^{2}$ and they account for $48 \%$ of the country's fertility. The total fertility rate in 2005-2006 was 2.7 children per woman, but there was much variation among states, from 2.0 (below replacement level) in Kerala to 4.0 in Bihar and 4.6 in Meghalaya. ${ }^{3}$

Early marriage and childbearing are common in India: The median age at marriage for females is 16.7 , well below the legal age of 18 , and $28 \%$ of women aged $20-49$ gave birth before age $18 .{ }^{l}$ Contraceptive use by mothers younger than 25 is negligible, resulting in short interpregnancy intervals. Women usually achieve their desired fertility of 2-3 children by age 25 and then adopt a permanent method.

Although contraceptive use among women younger than 25 is low, the demand for contraception in this population is high. (The National Family Health Survey classifies married women who want to wait at least two years before having a child or do not want any more children as

\footnotetext{
*The momentum effect in India can be explained as follows: Because of India's recent high fertility, a large number of young women will reach childbearing age in the coming years, and the absolute number of births by this cohort will be large even if the fertility rate reaches replacement level. Thus, despite the decreased level of fertility in India, population size will continue to grow for some years. The momentum effect can be lessened if age at first birth and spacing between subsequent births increase.
}

having a demand for contraception; those who want to wait at least two years before having a child or do not want any more children but are not using a contraceptive method are considered to have an unmet need for contraception. ${ }^{2}$ ) For example, in Bihar, where the mean age at cohabitation after marriage is just 17 , more than a third of married women aged 15-19 (34\%) and 20-24 (40\%) have a demand for contraception, and similar proportions (31\% and 33\%, respectively) have an unmeet need for contraception (primarily for spacing). ${ }^{4,5}$

The benefits of contraceptive use by young couples in India are many, especially in states where the age at marriage is very low, and levels of fertility, population growth infant and child mortality, and abortion are high. ${ }^{6}$ Delaying first births until age 21 and increasing the interval between the first and second births would help lower infant and child mortality, ${ }^{2,7}$ increase the mean age of childbearing and reduce India's high momentum effect* on population growth. ${ }^{8}$

Cultural barriers impede young women in rural India, especially northern India (including Bihar), from postponing childbearing. Parents and relatives are eager to see newly married women become pregnant and give birth soon after marriage and cohabitation. Many fear that the capacity for childbearing may decline with age, and there- 
fore believe it is wise to have children as early as possible. Moreover, persistent misconceptions about and distrust of spacing methods, such as the pill and the IUD, act as barriers to delaying childbirth. Village doctors and traditional birth attendants are among those who spread misconceptions about reproductive health care and family planning in rural areas.

The widespread use of condoms would not only reduce fertility but would protect young couples from STIs. A substantial proportion of young men in India leave their family homes and migrate from state to state for their livelihood; these young men are at risk for acquiring STIs, including HIV, because they frequently have sexual contact with sex workers, who have high rates of STIs. In surveys conducted for the Promoting Change in Reproductive Behavior in Bihar (PRACHAR) project, more than one in three women younger than 25 reported that their husband had been away from home for work in the past year. ${ }^{9}$

\section{Bihar State}

Roughly the size of Vietnam or the Philippines, Bihar is India's second most populous state, with 83 million people. Among India's 32 states, Bihar ranks last on the Indian government's human development index, a ranking that has not changed since 1981. ${ }^{10}$ Bihar's disadvantageous conditions can be attributed to numerous unfavorable and almost unchanging sociopolitical and economic factors. The region's economy depends largely on traditional agriculture, and most people live in rural areas and belong to underprivileged castes. The caste system is still powerful and deep-rooted; it hinders egalitarian access to resources and the development of skills necessary for social progress, and it reinforces continued poverty. Literacy is low, especially among women, although data from the National Family Health Survey indicate that it is increasing faster among young females than among young males. ${ }^{2}$ Labor force migration, both within and outside of the state, is increasing. Finally, road networks and availability of transportation are limited, hampering villagers' access to education, health care and modern goods. ${ }^{10}$

As a result, Bihar falls below the national average on almost all indicators of health, fertility and socioeconomic development. Childbearing begins very early in life: The mean age at first birth is 18.8. Contraceptive prevalence, though still low, increased from $22 \%$ to $31 \%$ between the $1998-$ 1999 and 2005-2006 National Family Health Surveys. ${ }^{4,5}$ Most of this improvement was due to an increase in sterilization among women older than 35; the increase in contraceptive use among women 25 or younger was negligible.

Bihar also fares poorly in immunization coverage and nutrition. Three in five children are underweight, and two in five are stunted. Three in four families have access to safe water, but only one in six have a toilet or latrine. Infant mortality remains high, at 62 per 1,000 births. Poor child health and high child mortality are likely associated with poor reproductive health indicators, including low use of contraceptives and short birth intervals. ${ }^{11-13}$

\section{THE PRACHAR INTERVENTION}

\section{Overview}

In 2001, Pathfinder International undertook the PRACHAR project to promote change in the reproductive behavior of youth in 19 administrative blocks (or subdistricts) of three of Bihar's districts: Nalanda, Nawada and Patna. These 19 blocks have a combined population of approximately 2.8 million; the intervention reached about 650,000 people, including approximately 110,000 unmarried adolescents, newlyweds, married women younger than 25 and their husbands. These areas are typical of Bihar's districts and are within 2-4 hours of the city of Patna (the state capital) by car or bus. The population in these districts is poor, has little education and belongs almost exclusively to scheduled and backward castes.

Between 2002 and 2006, 19 Bihar-based nongovernmental organizations worked with Pathfinder to implement the intervention. Each of these partners carried out the project in one intervention cluster that comprised 25-35 villages and approximately 30,000 residents; seven of the intervention clusters were in Nalanda, seven in Nawada and five in Patna. All of the partners used identical implementation approaches. Although the project is ongoing, changes were made in 2006 in the project design, intervention areas and population covered. This article reports on activities conducted under the original project design.

The goals of the PRACHAR project are to improve the health and welfare of young mothers and their children, improve the economic well-being of families and reduce population growth by changing social norms related to early childbearing. The project focuses on individuals who are young-adolescents as well as couples in which the wife is younger than 25-and have no more than one child. It promotes delaying the birth of one's first child until the mother is aged 21 , and the birth of a second child until 36 months after the first birth.

The promotion of contraceptive use is an important component of the project. The program's interventions were designed to educate adolescents, young adults and couples about reproductive health issues and to raise community awareness and support for delaying marriage and childbearing. A detailed description of PRACHAR interventions can be found elsewhere. ${ }^{9}$ Briefly, a favorable social environment was created through the orientation and training of reproductive health teams of community leaders and influential residents, and through group meetings with young couples' parents and in-laws; messages were disseminated through street theater performances and wall paintings; and formal and informal rural health service providers were trained on reproductive health issues and contraception (Table 1). In addition, unmarried adolescents received information through a three-day workshop, and newlywed couples via infotainment parties; group meetings were held for young married women and, separately, young married men; and young married women and men were counseled, separately, at home. 


\section{Project Personnel}

The personnel involved in the project were female change agents, male change agents, cluster supervisors, block-level project managers, training officers, district project officers, and the directors of the implementing partners. Their roles and responsibilities were as follows. Change agents and training officers provided information to young men and women; their work was monitored and supervised by cluster supervisors. Project managers, in turn, supervised all of the work in a block, and they organized (with help from cluster supervisors) activities related to social environment building and to improving access to reproductive health services. At the district level, the work was jointly supervised by the director of the implementing partner organization and the district officer.

Project training officers were responsible for training change agents and cluster supervisors. In addition, they trained village youth on street theater performance; educated chemists and village shopkeepers on the sale of oral contraceptives and condoms; trained rural practitioners, village reproductive health teams, and traditional birth attendants; and conducted educational workshops for unmarried young men and women and infotainment parties. Project trainers were themselves trained by a local training organization using materials and methodologies developed by Pathfinder International.

Recruitment of personnel followed Pathfinder's standard procedures, which require posting of job advertisements in local newspapers, at educational institutions and elsewhere. Female and male change agents generally had completed secondary school (10 years of schooling), although a few had only a seventh grade education; cluster supervisors were auxiliary nurse midwives who had had two years of vocational training after secondary school; project managers and training officers had at least a university education in the social sciences.

\section{Interventions}

The main target audience of the interventions, youth aged 15-24, was treated not as a homogenous group, but rather as subgroups with differing, life stage-specific needs: unmarried adolescents aged 15-19, newlyweds, women who were pregnant for the first time, and young married men and young married women with one child. Through workshops and behavior change communication, the interventions provided essential reproductive health information and addressed key issues of concern to young people at their particular stage of life. The topics presented in these targeted interventions were selected from a broad menu and included the basic structure and function of the reproductive system; the menstrual cycle; hygiene; nutrition; contraception; the transmission, prevention and treatment of STIs (including HIV) and reproductive tract infections; myths and misconceptions concerning sexuality, reproduction and STIs; recognizing and protecting against sexual harassment and abuse; spousal negotiation; genderegalitarian sexual decision making; the availability of
TABLE 1. Elements of PRACHAR interventions and the level at which they are likely to operate, 2002-2004

Element

Level

Social environment building

Formation of reproductive health teams comprising community

leaders and other influential community members

Orientation and training of reproductive health teams

Group meetings and infotainment programs for parents of young married men

Street theater performances

Wall paintings

Training rural providers in reproductive health and contraception

Providing information on reproductive health and services

Education of unmarried females aged 15-24 and unmarried males aged 15-24

Counseling through home visits to young women with $0-1$ child,

young married men without children, young women with first pregnancy

and young postpartum women who have delivered their first child

Infotainment parties for newly married couples

Educational meetings on reproductive health and contraception for

young married persons (separate meetings for women and men)

Improving access to reproductive health services

Facilitating monthly maternal and child health clinics conducted by government auxiliary nurse midwives

Encouraging young mothers and their children to obtain services from government maternal and child health clinics

Encouraging vulnerable and high-risk mothers and children to obtain referral services available at secondary- and tertiary-level health centers

Training rural health practitioners on reproductive health and family planning issues

Training traditional birth attendants on safe delivery, postpartum contraceptive counseling and referral of pregnant women with complications Motivating chemists and village convenience shops to keep regular stocks of condoms and pills

Community Community Community Community Community Community

Individual

Individual Couples

Group

Community

Community

Community

Community

Community

Community

reproductive health and family planning services; and the need to access and utilize services. The project selected media appropriate for the audience and the message being delivered.

PRACHAR's designers believed that behavior change would occur among young couples only if community knowledge were enhanced and if traditional beliefs and expectations about the number of children couples have, and the timing of births, were challenged. Thus, the project encouraged parents not to pressure young people to marry at a young age or to have children soon after marriage. Interventions emphasized that contraceptive use is safe and beneficial to the health of young mothers and their children; that the pill, the injectable, condoms and the standard days method can be used to delay or space births; and that the IUD is an effective long-term method. These messages were disseminated at the community level through meetings, street theater and wall paintings. Reproductive health teams supported change agents in orienting community leaders and other influential community members, including parents of young adults, to the idea of family planning and the healthy timing and spacing of pregnancies.

To reach young married women, a female change agent visited each young woman at her home every month to provide information and education. The change agent was a local resident who was responsible for visiting, talking to and following up on 100-125 young married women who had not yet had a child or who had only one child. She maintained records of her visits to each married woman 
TABLE 2. Percentage distribution of married women aged 15-24, by selected characteristics, according to area and survey, PRACHAR project, 2002-2004

\begin{tabular}{l} 
Characteristic \\
\hline Age \\
$15-19$ \\
$20-24$ \\
Parity \\
0 \\
1 \\
Yrs. of education \\
0 \\
$1-4$ \\
$5-9$ \\
$\geq 10$ \\
Caste \\
Scheduled caste/tribe \\
Most backward \\
Backward \\
Other \\
Totals
\end{tabular}

\begin{tabular}{ll|ll} 
Comparison & & \multicolumn{3}{l}{ Intervention } & \\
\hline $\begin{array}{l}\text { Baseline } \\
(\mathrm{N}=605)\end{array}$ & $\begin{array}{l}\text { Follow-up } \\
(\mathrm{N}=633)\end{array}$ & $\begin{array}{l}\text { Baseline } \\
(\mathrm{N}=1,390)\end{array}$ & $\begin{array}{l}\text { Follow-up } \\
(\mathrm{N}=1,447)\end{array}$ \\
\hline 50 & 43 & & \\
50 & 57 & 53 & 42 \\
& & & 58 \\
50 & 51 & 50 & \\
50 & 49 & 50 & 50 \\
& & & 50 \\
63 & 58 & 54 & \\
5 & 6 & 8 & 55 \\
17 & 20 & 20 & 22 \\
15 & 16 & 18 & 13 \\
& & & \\
43 & 36 & 27 & 35 \\
7 & 17 & 22 & 22 \\
40 & 38 & 34 & 35 \\
10 & 9 & 17 & 8 \\
100 & 100 & 100 & 100
\end{tabular}

and of changes in the woman's reproductive status. She also conducted group meetings with mothers-in-law and influential females in the community, and encouraged young unmarried women to attend educational programs. A male change agent, also a local resident, conducted periodic group meetings for men (separately for young married men, fathers-in-law and influential male community members), and encouraged unmarried young men to attend educational programs. He also counseled young married men at their homes. For the 19 partner organizations, 57 cluster supervisors supervised 228 female change agents and 114 male change agents.

During home visits, newly married women were counseled on delaying first births and on the correct and consistent use of the pill and condoms. Pregnant women received advice on antenatal care and safe delivery, and were educated on postpartum care, including exclusive breastfeeding, weaning, immunization, child nutrition and contraceptive use. Women who were pregnant for the first time were counseled to space their next birth by using contraceptives. They received information on where to obtain

\begin{tabular}{|c|c|c|}
\hline Measure & Comparison & Intervention \\
\hline \multicolumn{3}{|l|}{ Demand } \\
\hline Baseline & 23.8 & $25.0 \dagger$ \\
\hline Follow-up & $26.7 \neq$ & 40.2 \\
\hline \multicolumn{3}{|l|}{ Use } \\
\hline Baseline & 2.8 & $4.3 \dagger$ \\
\hline Follow-up & $4.7 \ddagger$ & 20.7 \\
\hline
\end{tabular}

health services for contraception, antenatal care, safe delivery, postpartum care and immunization. Change agents and cluster supervisors were responsible for providing information and referrals, but they did not distribute contraceptives or provide other medical services.

In order to enhance project beneficiaries' access to health services, a concerted effort was made to enable them to obtain these services in a timely way, with satisfaction, and without hassle. Project staff assisted government health workers in conducting maternal and child health clinics, and they encouraged young mothers (particularly those at high risk, such as teenagers and women with short interpregnancy intervals) and their children to obtain services. Rural medical practitioners, who have no formal medical training but are commonly used by villagers, were trained on spacing methods so that they could provide accurate information and not propagate negative myths about contraceptive methods or otherwise contradict the messages disseminated by PRACHAR. Traditional birth attendants were trained on safe delivery and modern spacing methods. PRACHAR workers also encouraged the chemist or convenience shop in each village to maintain regular supplies of pills and condoms.

Implementation began in July 2002 in Nalanda, in October 2002 in Nawada and in April 2003 in Patna. The first phase of PRACHAR ended in 2005-2006. Phase II is currently being implemented and will continue through July 2009.

\section{METHODS}

The outcomes of Phase I were evaluated by collecting and comparing data from two rounds of surveys conducted in the intervention areas and in comparable areas with no intervention. The comparison areas were chosen because their socioeconomic conditions and accessibility were similar to those of the intervention communities.

The surveys gathered information on demand for contraception, contraceptive use, and knowledge and attitudes that influence childbearing and spacing behaviors. The first survey was conducted in 2002-2003, before the interventions had begun; the second was conducted in 2004, after 21-27 months of intervention. A cluster sampling procedure was used to select respondents for the evaluation surveys. ${ }^{14}$ In Nalanda, respondents were selected from both intervention areas and comparison areas; in Nawada and Patna, only intervention areas were sampled, as the comparison areas in Nalanda bordered those two districts and are comparable to the intervention areas in all three districts.

In Nalanda, 20 clusters (villages) were selected from the seven intervention areas and 20 from the seven comparison areas. Each comparison area was located within five kilometers of the intervention areas in the district. Six hundred married women younger than 25, half of whom had no child and half one child, were selected from the intervention areas; an equal number were selected from comparison areas. The sampling procedure was slightly differ- 
ent in Nawada and Patna: In each district, 13 clusters were chosen, from which a sample of 390 women, half with no child and half with one child, was obtained.

The villages were selected from a list of all villages in the intervention areas stratified by population size $(<1,000$, 1,000-2,000 and >2,000); the probability of selection was proportionate to size. An index household was chosen in a quasi-random manner from each selected village, and the investigator moved from household to household, in a predetermined direction, interviewing eligible women. The sample in the cluster was considered complete when 15 women with no child and 15 with one child had been interviewed. The samples were drawn independently, and the sampling techniques were identical, in the baseline and follow-up surveys. In total, 1,995 women were interviewed in the baseline survey, and 2,080 were interviewed in the follow-up survey.

The baseline survey was conducted 1-2 months prior to the initiation of intervention activities, in April-May 2002 in Nalanda, and February 2003 in Nawada and Patna. The follow-up survey was conducted in all communities in October-December 2004. Trained interviewers collected data using a structured, pretested questionnaire. Supervisors monitored the interviewers' work, verified the accuracy of selected responses and made any needed corrections on the completed questionnaires in the field.

The current study focuses on five measures from the questionnaires. Two of the measures assessed respondents' attitudes: whether they agreed that early childbearing is injurious to the mother's health and that contraceptive use is safe and necessary for delaying a first birth. Another measure assessed whether respondents knew that a woman's fertility varies during the menstrual cycle. The final measures were whether the respondent had a demand for contraception and whether she was using a method.

\section{Data Analysis}

Data were analyzed using SPSS. Outcomes were compared between surveys and between the intervention and comparison communities. Data for intervention and comparison areas and at baseline and follow-up were merged. The effect of the interventions on contraceptive use was analyzed using a logistic regression model that controlled for socioeconomic and other factors, including women's age, parity, education, caste and intervention district. In addition, we examined the interaction between intervention area and survey; this analysis made it possible to see if any changes in outcomes between surveys were greater or smaller in the intervention areas than in the comparison areas. Analyses controlled for district because the duration of exposure to interventions varied: The interventions lasted 21 months in Patna, 24 months in Nawada and 27 months in Nalanda.

\section{RESULTS}

Respondents were generally similar across survey areas in age, number of children, education and caste (Table 2). More than half of the young women had not had any
TABLE 4. Percentage of married women aged 15-24 with correct responses to fertilityrelated measures, by area and survey

\begin{tabular}{lcc|l|l} 
Measure & \multicolumn{2}{l|}{ Comparison } & \multicolumn{2}{l}{ Intervention } \\
\cline { 2 - 5 } & Baseline & Follow-up & Baseline & Follow-up \\
\hline $\begin{array}{l}\text { Agreed that early childbearing is } \\
\text { injurious to mother's health }\end{array}$ & $12 \dagger$ & $65 \ddagger$ & 17 & $74 \S$ \\
$\begin{array}{l}\text { Agreed that contraceptive use is safe } \\
\text { and necessary for delaying first birth } \\
\begin{array}{l}\text { Knew about fertile days in the } \\
\text { menstrual cycle }\end{array}\end{array}$ & 36 & $72 \ddagger$ & 38 & $80 \S$ \\
\hline
\end{tabular}

†Significantly different from the percentage at baseline for the intervention area at $p<.05$. $¥$ Significantly different from the percentage at follow-up for the intervention area at $p<.01$. §Significantly different from the percentage at baseline for the intervention area at $p<.001$. + Significantly different from the percentage at followup for the intervention area at $\mathrm{p}<.001$.

schooling, and approximately nine in 10 were from disadvantaged backward classes or scheduled castes. Although the samples were independently drawn, there were no apparent differences between participants at baseline and those at follow-up.

At baseline, the demand for contraception in the comparison areas was similar to that in the intervention areas: Approximately one-fourth of women indicated that they wanted to wait at least two years for a child (or their next child) or wanted no more children (Table 3). By follow-up, demand for contraception had increased to $40 \%$ in the intervention areas. In contrast, demand showed little change in the comparison areas.

Contraceptive use was similar in the two areas at baseline: $3 \%$ of women in the comparison areas and $4 \%$ of those in the intervention areas reported using a method. At follow-up, contraceptive use had risen only slightly, to $5 \%$, in the comparison areas, but had increased significantly, to $21 \%$, in intervention communities. Thus, three comparisons point to the interventions having a positive

FIGURE 1. Percentage of married women aged 15-24 using contraceptives, by area, survey and number of children

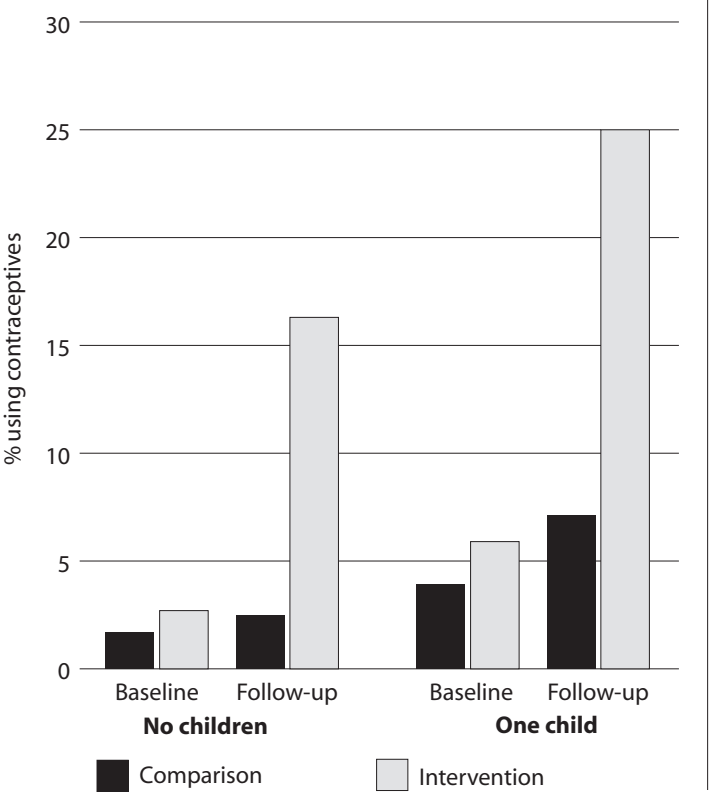


TABLE 5. Odds ratios from logistic regression analysis of associations between selected characteristics and young married women's attitudes, knowledge and contraceptive behavior

\begin{tabular}{|c|c|c|c|c|c|}
\hline \multirow[t]{2}{*}{ Characteristic } & \multicolumn{2}{|l|}{ Attitudes } & \multirow{2}{*}{$\begin{array}{l}\text { Knowledge } \\
\text { Knew about } \\
\text { fertile days in } \\
\text { the menstrual } \\
\text { cycle }\end{array}$} & \multicolumn{2}{|c|}{$\begin{array}{l}\text { Contraceptive } \\
\text { behavior }\end{array}$} \\
\hline & $\begin{array}{l}\text { Agreed that } \\
\text { early child- } \\
\text { bearing } \\
\text { is injurious to } \\
\text { mother's } \\
\text { health }\end{array}$ & $\begin{array}{l}\text { Agreed that } \\
\text { contraceptive } \\
\text { use is safe and } \\
\text { necessary for } \\
\text { delaying first } \\
\text { birth }\end{array}$ & & Demand & Use \\
\hline \multicolumn{6}{|l|}{ Area } \\
\hline Comparison (ref) & 1.00 & 1.00 & 1.00 & 1.00 & 1.00 \\
\hline Intervention & $1.69^{* * *}$ & 1.00 & 0.70 & 1.00 & 1.40 \\
\hline \multicolumn{6}{|l|}{ Survey } \\
\hline Baseline (ref) & 1.00 & 1.00 & 1.00 & 1.00 & 1.00 \\
\hline Follow-up & $19.51^{* * *}$ & $5.01^{* * *}$ & 1.07 & 1.16 & 1.60 \\
\hline Area x survey & $2.61^{* *}$ & $1.57^{* *}$ & $2.97^{* * *}$ & $1.49^{* *}$ & $3.84^{* * *}$ \\
\hline \multicolumn{6}{|l|}{ Age } \\
\hline $15-19$ (ref) & 1.00 & 1.00 & 1.00 & 1.00 & 1.00 \\
\hline $20-24$ & $1.30^{* *}$ & $1.21^{* *}$ & $1.41^{* * *}$ & 0.51 & 1.06 \\
\hline \multicolumn{6}{|l|}{ Parity } \\
\hline 0 (ref) & 1.00 & 1.00 & 1.00 & 1.00 & 1.00 \\
\hline 1 & 1.20 & 0.89 & $1.73^{* * *}$ & $3.96^{* * *}$ & $1.83^{* * *}$ \\
\hline \multicolumn{6}{|l|}{ Yrs. of education } \\
\hline 0 (ref) & 1.00 & 1.00 & 1.00 & 1.00 & 1.00 \\
\hline$\geq 1$ & $1.52^{* * *}$ & $2.42^{* * *}$ & $1.85^{* * *}$ & $1.59^{* * *}$ & $2.55^{* * *}$ \\
\hline \multicolumn{6}{|l|}{ Caste } \\
\hline Scheduled caste/tribe & 0.86 & 0.67 & $0.81^{*}$ & 1.16 & 0.83 \\
\hline Most backward & 1.14 & 0.89 & 1.01 & 1.04 & 0.96 \\
\hline Backward (ref) & 1.00 & 1.00 & 1.00 & 1.00 & 1.00 \\
\hline Other & 0.93 & 0.93 & 1.11 & 1.08 & 0.93 \\
\hline \multicolumn{6}{|l|}{ District } \\
\hline Nalanda (ref) & 1.00 & 1.00 & 1.00 & 1.00 & 1.00 \\
\hline Nawada & $0.71^{*}$ & 0.93 & 0.83 & $1.28^{* *}$ & 0.96 \\
\hline Patna & $0.66^{* *}$ & $0.72^{* *}$ & $1.42^{* * *}$ & $1.44^{* *}$ & 1.02 \\
\hline Model constant & -0.02 & -1.08 & -2.03 & -1.92 & -4.28 \\
\hline -2LogLikelihood & $2,908.80$ & $4,672.82$ & $4,318.46$ & $4,529.35$ & $2,252.78$ \\
\hline
\end{tabular}

effect: Contraceptive use increased in the intervention areas between surveys; at follow-up, contraceptive use in the intervention areas was higher than that in the comparison areas; and the change in contraceptive use that occurred between surveys was greater in the intervention areas than in the comparison areas.

The rise in contraceptive prevalence in the intervention areas was due primarily to increased use of the pill and condoms (not shown). At follow-up, about $5 \%$ of women in the intervention areas were using the pill and $13 \%$ were using condoms. Use of other methods was low (0-2\%), and was comparable between areas and surveys.

Knowledge and attitudes improved over time in both the intervention and the comparison communities. For example, the proportion of respondents who agreed that early childbearing is injurious to a mother's health increased from $12 \%$ to $65 \%$ in the comparison areas and from $17 \%$ to $74 \%$ in the intervention areas (Table 4, page 193). The proportion of women who agreed that contraceptive use is safe and nec- essary for delaying a first birth increased in both areas. However, at follow-up, this agreement was significantly higher in the intervention areas than in the comparison areas.

In addition, women in the intervention areas showed improvement in knowledge of the fertile days in the menstrual cycle. At follow-up, 39\% of women knew about fertile days in the cycle, compared with only $18 \%$ at baseline. In the comparison areas, the level of knowledge remained essentially unchanged, at around $20 \%$ in both surveys.

Contraceptive use increased in the intervention areas regardless of parity (Figure 1, page 193). At baseline, contraceptive use among childless women was low in both the intervention areas (3\%) and the comparison areas (2\%). At follow-up, it had increased to $16 \%$ in the intervention areas ( $<.01$ ), but to only $3 \%$ in the comparison areas (change not statistically significant). Similarly, among women with one child, contraceptive use increased fourfold, from $6 \%$ to $25 \%(\mathrm{p}<.001)$, in the intervention areas, but the change in the comparison areas (from $4 \%$ to $7 \%$ ) was not statistically significant.

Our logistic regression analysis focused on two independent variables (intervention area and survey) and one interaction term (area x survey). Attitudes toward early childbearing were more favorable in the intervention area, and improved from baseline to follow-up (Table 5), findings similar to those in the bivariate analysis. The interaction term indicates that the increase in the intervention area was 2.6 times that in the comparison area. Similarly, findings for the other attitudinal measure show that attitudes toward contraceptive use improved between surveys (odds ratio, 5.0) and improved by a greater degree in the intervention area than in the comparison area (1.6).

Knowledge about fertile days did not differ between areas at baseline, and did not differ significantly between surveys. However, the interaction term showed that knowledge increased to a greater extent in the intervention area than in the comparison area (odds ratio, 3.0).

At baseline, contraceptive demand and use did not differ between the intervention and comparison areas, and they remained virtually unchanged between surveys when data from both areas were combined. But both measures increased significantly between surveys in the intervention area. The increase in demand for contraception between surveys in the intervention area was 1.5 times that in the comparison area, and the increase in contraceptive use was even more pronounced (odds ratio, 3.8).

The multivariate analysis also revealed associations between attitudes, knowledge and contraceptive behavior and the other independent variables. Age was positively associated with the measures of knowledge and attitudes. Knowledge of fertile days and the demand for and use of contraceptives were significantly higher among women with one child than among those with no children. Women with one or more years of schooling had a higher level of knowledge, more favorable attitudes, and greater demand for and use of contraceptives than did women with no education. None of these measures varied by 
caste, except that knowledge of fertile days was lower among women in the scheduled caste/tribe group than among those in the backward castes. Knowledge, attitudes and demand for contraception differed among districts, but contraceptive use did not.

\section{DISCUSSION}

In this study, we compared family planning attitudes, knowledge and behavior among young women before and after implementation of the PRACHAR project in Bihar, and we compared postimplementation outcomes in intervention areas with those from comparison areas. We documented that contraceptive use by young couples to delay and space first and second births, as well as the demand for contraception, both increased in the intervention areas following implementation of the project. The results are consistent with findings from the National Family Health Survey, which showed that young women have a strong desire to delay and space their pregnancies. ${ }^{4}$

PRACHAR behavior change communication interventions were directed not only at youth and young couples, but also at their parents, their in-laws and influential community members, all of whom may shape the reproductive decision making of young people. It was expected that providing information about reproductive health and sexuality to young people would pose significant challenges because of community taboos against discussion of these topics. But because the project involved all major stakeholders, it was able to positively affect behavior and increase young couples' contraceptive use.

The project emphasized generating demand for family planning services, and our results suggest that this approach can increase method use for spacing purposes even when contraceptive provision is not a part of the intervention. Although tested here in rural areas, the PRACHAR model is replicable throughout Bihar and has relevance in other contexts where youth fertility is high and delaying and spacing children is important.

The PRACHAR project introduced young people and their families to basic information about caring for their own health and the economic advantages of delaying and spacing births. Many of these youth encountered for the first time the idea of planning for the birth of their children. That led to imagining-and then planning-a desirable future, making choices and envisioning possibilities for improvements.

Although we found substantial positive changes in attitudes toward using contraceptives and delaying childbirth in both the comparison and intervention areas, the changes were greater in the latter. The routine visits (approximately every six months) we made to the comparison areas during the project indicated that the changes in the comparison areas were not due to any local interventions. However, we do know that the comparison areas are not isolated communities; they are open to broader cultural and social influences in the state and country.

Three factors may have been particularly important in shaping attitudes: Rapid and remarkable economic, social and ideational transformation has occurred in all of India over the past several decades; the government and other agencies have invested heavily in print, radio and television campaigns that promote key social issues, such as the benefits of delaying marriage, limiting family size and practicing contraception; and seasonal and annual employment-related migration of young men from rural areas to urban ones, both within and outside the state and country, has helped to disseminate new ideas and social change. In addition, according to data from the National Family Health Survey, the proportion of individuals who were aware of specific contraceptive methods increased substantially in Bihar between 1998-1999 and 20052006 -from $77 \%$ to $96 \%$ for the pill, $62 \%$ to $79 \%$ for the IUD and $67 \%$ to $82 \%$ for condoms. ${ }^{4,5}$ However, contraceptive use by young couples increased only marginally, from $0.5 \%$ to $1.4 \%$ among couples with no children, and from $4 \%$ to $6 \%$ among couples with one child. As noted above, we also observed small, nonsignificant changes in contraceptive use among couples with one or no children, findings similar to those of the National Family Health Survey.

The changes we observed in the PRACHAR intervention areas were markedly different. First, the degree of attitudinal change was greater in the intervention areas than in the comparison areas. Second, communities in the intervention areas moved further along the behavior change spectrum-beyond attitudinal change to actual use of contraceptives-than did those in the comparison areas. We believe that this was because young couples who were exposed to the full range of behavior change communication methods used by PRACHAR were better able to interpret and evaluate information. Our findings indicate that ideational change may not be sufficient to promote behavioral change unless specific information is provided and a supportive environment is created, as was done in PRACHAR.

The speed with which change occurred in what are believed to be deeply held beliefs and traditional behaviors suggests that conditions in Bihar and similar rural Indian communities are ripe for change: Demand for contraception exists, and many people want to control their reproductive lives by spacing and limiting their births. Well-designed programs can quickly convert demand to use. The rapidity with which contraceptive acceptance occurred in PRACHAR intervention areas is not unprecedented, as other successful community-based family planning projects have been reported (those projects, however, involved couples of higher parity than those in PRACHAR). The Matlab project in Bangladesh is a renowned example. ${ }^{15,16}$ In the mid-1970s, in religiously conservative villages with poor socioeconomic conditions, educated local women offered doorstep family planning counseling and services. In less than a year, the prevalence of contraceptive use increased from $5 \%$ to nearly $20 \%$. The success of the program was sustained, the range of services offered was gradually expanded, and nu- 
merous studies have documented the project's impact on fertility and other reproductive health behavior, as well as its scaling-up in the public sector. ${ }^{17}$

During the 1990s, community-based distribution programs in South Asia and Africa produced sharp increases in the knowledge and use of contraceptives. ${ }^{18,19}$ A principal difference between community-based distribution programs and PRACHAR is that the latter does not provide services; rather, it generates demand for services and provides information on where services are available. In Uttar Pradesh, another disadvantaged state in India, providing carefully designed, community-oriented information through meetings, leaflets and posters has been shown to be a powerful means of generating demand for and utilization of health and social services. ${ }^{20}$ After only one year, use of prenatal care, maternal immunization and child immunization all increased in the project area. In rural Nepal, an intervention in which information on antenatal, delivery and neonatal care was provided through women's groups was successful: In about two years, neonatal and maternal mortality declined significantly in the intervention communities. ${ }^{21}$

\section{Limitations and Future Developments}

Some behaviors are slower to change than others. Persuading young couples to delay their first birth will take longer than convincing them of the benefits of spacing births or of limiting family size. PRACHAR has successfully raised awareness and support for family planning and birth spacing in intervention communities, and it has shown that it is possible to persuade young couples to use contraceptives. However, it remains to be seen whether the observed changes in contraceptive use among young couples will translate into delayed and spaced births. One limitation of the surveys we used is that they did not provide data on actual fertility, which would have allowed us to measure the interventions' effects on birth intervals and spacing.

An analysis of data collected through PRACHAR's monitoring, information and evaluation system is under way to address this and other issues. During PRACHAR's second phase, Pathfinder will continue to measure the longterm impact of training and other interventions on the sexual and reproductive decision making of youth, including the program's impact on fertility. It will also study whether the same level of results can be achieved with a simpler and more economical package of PRACHAR interventions.

Another limitation of this analysis is that we could not separate the effects of individual intervention components. We do not know, for example, how the contribution of the activities designed to enhance accessibility of reproductive health and related services compared to the contribution of the core interventions (e.g., home visits, group meetings). The ongoing second phase of PRACHAR will allow the effects of individual components to be identified.

\section{REFERENCES}

1. Haub C and Sharma OP, India's population reality: reconciling change and tradition, Population Bulletin, 2006, Vol. 61, No. 3.
2. International Institute for Population Sciences (IIPS) and ORC Macro, National Family Health Survey (NFHS-2), 1998-1999: India, Mumbai: IIPS, 2000

3. IIPS, 2005-2006 National Family Health Survey (NFHS-3): National Fact Sheet, India (Provisional Data), Mumbai: IIPS, 2007.

4. IIPS and ORC Macro, National Family Health Survey (NFHS-2), India, 1998-1999: Bihar, Mumbai: IIPS, 2001

5. IIPS, 2005-2006 National Family Health Survey (NFHS-3): Fact Sheet, Bihar (Provisional Data), Mumbai: IIPS, 2007

6. Khan ME et al., Abortion in India: current situation and future challenges, in: Pachauri S, ed., Implementing a Reproductive Health Agenda in India: The Beginning, New Delhi: Population Council, 1999, pp. 507529

7. Rutstein S, Effect of birth intervals on mortality and health: multivariate cross-country analysis, paper presented at the Conference on Optimal Birth Spacing for Central America, Antigua, Guatemala, June 2003.

8. Bongaarts J, Population policy options in the developing world, Science, 1994, 263(5148):771-776

9. Wilder J, Masilamani R and Daniel EE, Promoting Change in the Reproductive Behavior of Youth: Pathfinder International's PRACHAR Project, Bihar, India, Watertown, MA, USA: Pathfinder International, 2005.

10. Planning Commission, Government of India, National Human Development Report 2001, New Delhi: Government of India, 2002.

11. Govindasamy P et al., High-risk births and maternity care, DHS Comparative Studies, Columbia, MD, USA: Macro International, 1993 , No. 8 .

12. Rutstein SO, Effects of preceding birth intervals on neonatal, infant and under-five years mortality and nutritional status in developing countries: evidence from the Demographic and Health Surveys, International Journal of Gynecology \& Obstetrics, 2005, 89(Suppl. 1):S7S24.

13. Rahman M, The effect of child mortality on fertility regulation in rural Bangladesh, Studies in Family Planning, 1998, 29(3):268-281.

14. Institute for Research in Medical Statistics (IRMS), Methodological Investigations on Surveys of Immunization Coverage, New Delhi: IRMS, 1991.

15. Bhatia S et al., The Matlab family planning-health services project, Studies in Family Planning, 1980, 11(6):202-212.

16. Phillips JF et al., The demographic impact of the family planning-health services project in Matlab, Bangladesh, Studies in Family Planning, 1982, 13(5):131-140.

17. Phillips JF et al., Transferring health and family planning service innovations to the public sector: an experiment in organization development in Bangladesh, Studies in Family Planning, 1984, 15(2):62-73.

18. Katz KR et al., Increasing access to family planning services in rural Mali through community-based distribution, International Family Planning Perspectives, 1998, 24(3):104-110.

19. Shelton JD et al., Putting unmet need to the test: community-based distribution of family planning in Pakistan, International Family Planning Perspectives, 1999, 25(4):191-195.

20. Pandey $\mathrm{P}$ et al., Informing resource-poor populations and the delivery of entitled health and social services in rural India: a cluster randomized controlled trial, Journal of the American Medical Association, 2007, 298(16):1867-1875.

21. Manandhar DS et al., Effect of a participatory intervention with women's groups on birth outcomes in Nepal: cluster-randomised controlled trial, Lancet, 2004, 364(9438):970-979.

\section{RESUMEN}

Contexto: El uso de anticonceptivos por parejas jóvenes en India es bajo; y son comunes la maternidad temprana y los intervalos cortos entre nacimientos. El Proyecto PRACHAR, una intervención continua en el estado de Bihar, busca aumentar 
el uso de anticonceptivos para retrasar y espaciar los nacimientos a través de intervenciones de comunicación.

Métodos: En 2002-2003, se encuestó a muestras aleatorias de mujeres casadas menores de 25 años con no más de un hijo, antes de que el proyecto PRACHAR fuese implementado ( $N=1,995)$; y en 2004, unos 21-27 meses después de la implementación ( $N=2,080)$. Las diferencias en la demanda y uso de anticonceptivos, así como en las actitudes y conocimientos relacionados, se evaluaron entre las dos encuestas y también entre las áreas de intervención y las áreas de comparación. Se usó regresión logística para evaluar el efecto de las intervenciones sobre estos indicadores.

Resultados: El uso de anticonceptivos fue muy bajo (2-6\%) en la encuesta de línea de base, tanto en las áreas de comparación como en las de intervención. La demanda por anticoncepción aumento del $25 \%$ en la línea de base al $40 \%$ en el seguimiento en las áreas de intervención, pero se mantuvo virtualmente sin cambios en las áreas de comparación. En la encuesta de seguimiento, el uso de anticonceptivos había aumentado en ambas áreas, pero las probabilidades ajustadas de uso en las áreas de intervención fueron 3.8 veces mayores que las de las áreas de comparación. Las mujeres en las áreas de intervención tenían unas probabilidades elevadas de saber que la fecundidad varía durante el ciclo menstrual; así como de estar de acuerdo en que la maternidad temprana puede ser dañina y que el uso de anticonceptivos es necesario y seguro para retrasar los primeros nacimientos (razones de momios, 1.6-3.0).

Conclusión: Los programas de comunicación culturalmente apropiados y basados en la comunidad, que están dirigidos a jóvenes y a quienes influyen en sus decisiones, pueden crear demanda por la anticoncepción en parejas jóvenes y conducir a un mayor uso de anticonceptivos.

\section{RÉSUMÉ}

Contexte: La pratique contraceptive parmi les jeunes couples d'Inde est faible et la procréation précoce, de même que les intervalles de naissance brefs, sont fréquents. Le projet PRACHAR, campagne continue au Bihar, cherche à accroître la pratique contraceptive en vue de différer et d'espacer les naissances, par le biais d'interventions de communication.
Méthodes: Des échantillons aléatoires de femmes mariées de moins de 25 ans et mères d'au plus un enfant ont été interviewés en 2002-2003, avant la mise en œuvre de PRACHAR $(N=1.995)$, et en 2004, 21 à 27 mois après la mise en ouvre $(N=2.080)$. Les différences au niveau de la demande et de la pratique contraceptive, ainsi que des attitudes et connaissances afférentes, ont été évaluées d'une enquête à l'autre et dans les zones d'intervention par rapport aux zones de comparaison. L'effet des interventions sur ces indicateurs a été évalué par régression logistique.

Résultats: La pratique contraceptive s'est révélée très faible ( $2 \%$ à $6 \%$ ), au niveau de référence, tant dans les zones de comparaison que d'intervention. La demande de contraception est passée de $25 \%$ au niveau de référence à $40 \%$ au suivi dans les zones d'intervention, tandis qu'elle demeurait virtuellement inchangée dans celles de comparaison. Au suivi, la pratique contraceptive avait augmenté dans les deux groupes, mais la probabilité ajustée de pratique dans les zones d'intervention s'est avérée 3,8 fois supérieure à celle des zones de comparaison. Dans les zones d'intervention, il s'est avéré fort probable que les femmes sachent que la fécondité varie pendant le cycle menstruel et conviennent que la maternité précoce peut être préjudiciable et que la pratique contraceptive est nécessaire et sûre si l'on veut différer les premières naissances (rapports de probabilités 1,6-3,0).

Conclusion: Des programmes de communication communautaires adaptés à la culture locale, ayant pour cible les jeunes et les personnes qui influencent leurs décisions, peuvent susciter une demande de contraception parmi les jeunes couples et mener à une pratique contraceptive accrue.

\section{Acknowledgments}

Support for the PRACHAR Project is provided by the David and Lucile Packard Foundation. The authors thank Amy Tsui for her comments on the manuscript and for her suggestions regarding analytical approaches, her staff for their help in data analysis, Stan Becker and Julie DaVanzo for their comments on the paper and Kate Schaffer for editing the manuscript.

Author contact: MizanurRahman@pathfind.org 